\title{
Salmonella enterica subsp. enterica Serovar gallinarum
}

National Cancer Institute

\section{Source}

National Cancer Institute. Salmonella enterica subsp. enterica Serovar gallinarum. NCI

Thesaurus. Code C124376.

A gram negative, rod shaped, non-motile serotype of the bacteria genus Salmonella, species Salmonella enterica, subspecies enterica. Salmonella Gallinarum, one of two poultry-adapted strains of Salmonella bacteria, causes fowl typhoid. 